\title{
IMPLEMENTASI ALGORITMA APRIORI UNTUK MENENTUKAN KEPUASAN MAHASISWA TERHADAP PELAYANAN SIM ONLINE UNIVERSITAS WIDYAGAMA MALANG
}

\author{
Ibnu Mubarok'1), Fitri Marisa'2), Dwi Purnomo3) \\ ${ }^{1)}$ Mahasiswa Fakultas Teknik, Universitas Widyagama \\ Email: ibnumubarok99@gmail.com \\ 2,3) Fakultas Teknik, Universitas Widyagama \\ Email: fitrimarisa@widyagama.ac.id ${ }^{2)}$,purnomo_it@yahoo.com ${ }^{3)}$
}

\begin{abstract}
Information system is a medium to accommodate an activity that takes place in an agency or institution, whether it is administrative activities and activities in a non-administration. Therefore, the information system is needed as supporting the publishing or storage database of an agency. A good information system will greatly support the educational activities of an institution or educational institution one of them is academic system information system which includes data processing related data entities, lessons, schedules, and so forth. From the definition of standard website quality, it can be concluded that the quality of website services in university widyagama malang not reach the criteria specified by the standard ISO 8402. So that most of the users among university students Widyagama Malang many who complain to the service website itself, Are: a lot of unpublished student value, delinquent financing arrears, and many other service deficiencies on the website. So that made the system Implementation of Apriori Algorithm To Determine Student Satisfaction Of Online SIM Service Widyagama University of Malang. To find the level of student satisfaction dihadapat wice online service wydiagama unfortunate.
\end{abstract}

Keywords : apriori algorithm, SIM online

\section{PENDAHULUAN}

Sistem informasi adalah sebuah media untuk mengakomodasi sebuah kegiatan yang berlangsung pada suatu instansi atau lembaga, baik itu kegiatan secara administrasi maupun kegiatan secara non administrasi. Oleh karena itu, sistem informasi sangat diperlukan sebagai penunjang pempublikasian atau penyimpanan database suatu instansi. Sistem informasi yang baik akan sangat menunjang kegiatan pendidikan pada suatu instansi atau lembaga pendidikan salah satunya yaitu sistem informasi sistem akademik yang meliputi pengolahan data entitas data yang terkait, pelajaran, jadwal, dan lain sebagainya.

Adapun pengertian standat kualitas website menurut ISO 9402 adalah keseluruhan fitur dan karakteristik produk software yang mendukung kemampuan untuk memuaskan kebutuhan yang diinginkan. Kualitas website dari sudut pandang kepuasan user adalah mengevaluasi kualitas isi yang terdapat pada website dalam beberapa hal seperti navigasi, keindahan, fungsi, dan hal lainnya yang 
mempengaruhi [1] (Luis Olsina, 2006). Kepuasan User merupakan ukuran penting kualitas website, Data kepuasan user diambil dengan ukuran standar penggunaan website sehingga penilaian kualitas diperoleh secara menyeluruh [2](Bailin \& Pullinger, 2010).

Dari pengertian standat kualitas website diatas, dapat disimpulkan bahwa kualitas pelayanan website yang ada di universitas widyagama malang belum mencapai kriteria-kriteria yang ditentukan oleh standat ISO 8402. Sehingga kebanyakan dari user di kalangan mahasiswa universitas widyagama malang banyak yang mengeluh terhadap pelayanan website itu sendiri, diantaranya adalah: banyak nilai mahasiswa yang belum terpublikasi, tunggakan-tunggakan pembiayaan yang tidak sesuai dengan kenyataan, dan banyak lagi kekurangankekurangan pelayanan pada website tersebut. Berdasarkan permasalahan diatas, maka penulis membuat judul penelitian "Implementasi Algoritma Apriori untuk Menentukan Kepuasan Mahasiswa Terhadap Pelayanan SIM Online Universitas Widyagama Malang".

\section{LANDASAN TEORI}

\section{A. Pengertian Algoritma Apriori}

Algoritma Apriori adalah salah satu algoritma yang melakukan pencarian frequent itemset dengan menggunakan teknik association rule [3](Erwin, 2009).

Pada algoritma Apriori menentukan kandidat yang mungkin muncul dengan cara memperhatikan minimum support dan minimum confidence. Support adalah nilai pengunjung atau persentase kombinasi sebuah item dalam database. Rumus support adalah sebagai berikut:

$$
\begin{gathered}
\text { Support }(A, B)=P(A \cap B) \\
\text { Support }(A, B)= \\
\frac{\sum \text { Transaksi mengandung } A \text { dan } B}{\sum \text { Total Transaksi }} \times 100 \\
\%
\end{gathered}
$$

B. Kualitas

Definisi kualitas menurut produsen adalah kesesuaian terhadap spesifikasi, dimana produsen memberikan toleransi tertentu yang dispesifikasikan untuk dimensi-dimensi kritis dan tiap bagian yang dihasilkan. Pada bidang jasa, kualitas dipertahankan dengan memenuhi standar pelayanan. Dari sudut pandang konsumen, kualitas berarti nilai yaitu seberapa baik suatu produk atau jasa menyajikan tujuan yang dimaksudkan dengan tingkat harga yang bersedia dibayar oleh konsumen. Crosbymendefinisikan Kualitas adalah kesesuaian terhadap persyaratan. [4](Crosby:1996).

Sementara Kualitas menurut ISO didefinisikan sebagai derajat atau tingkat karakteristik yang melekat pada produk atau jasa yang mencukupi persyaratan atau keinginan. Menurut Tjiptono [5](1996:51) kualitas merupakan suatu kondisi dinamis yang berhubungan dengan produk jasa, manusia, proses dan lingkungan yang memenuhi atau melebihi harapan. Deming dalam Tjiptono [6](1997:7) mendefinisikan kualitas menurut konteks, persepsi customer dan kebutuhan serta kemauan customer, yaitu:

a. Kualitas bergantung pada apa yang dikehendaki dan dibutuhkan oleh customer.

b. Kualitas adalah penilaian subyektif customer. Penilaian ini ditentukan oleh persepsi customer dalam melihat seta merasakan apa yang sudah didapat terhadap produk atau jasa. Jadi yang penting adalah bagaimana produk atau 
jasa dipersepsikan oleh customer dan kapan persepsi customer berubah.

c. Kualitas tidak dapat didefinisikan apabila tidak dikaitkan dengan suatu konteks tertentu. Kualitas adalah suatu karakteristik atau atribut daripada sesuatu. Jadi untuk mendefinisikan kualitas terlebih dahulu harus menentukan sesuatu.

C. Kepuasan

Kata kepuasan (satisfaction) berasal dari bahasa latin "satis" (artinya cukup baik, memadai) dan "facio" (melakukan atau membuat). Kepuasan bisa diartikan sebagai "upaya pemenuhan kebutuhan" atau "membuat sesuatu memadai". Oxford Advance Learner's Dictionary dalam Tjiptono [7](2005:195) mendeskripsikan kepuasan sebagai the good feeling that you have when you achieved something or when something that you wanted to happen does happen. Artinya sebuah perasaan bahagia ketika mendapatkan sesuatu atau ketika sesuatu yang diinginkan terjadi. Cadotte, Woodruff \& Jenkins dalam Tjiptono [8](2005:197) kepuasan dikonseptualisasikan sebagai perasaan yang timbul setelah mengevaluasi pengalaman. Oliver dalam Tjiptono [9](2005:197) kepuasan adalah fenomena rangkuman atribut bersama - sama dengan emosi konsumsi lainnya.

\section{A. Pengertian Pelayanan}

Publik Jasa sering dipandang sebagai suatu fenomena yang rumit. Kata jasa itu sendiri mempunyai banyak arti, dari mulai pelayanan personal (personal service) sampai jasa sebagai produk. Berbagai konsep mengenai pelayanan banyak dikemukakan oleh para ahli seperti Haksever et al [10](2000) menyatakan bahwa jasa atau pelayanan (services) didefinisikan sebagai kegiatan ekonomi yang menghasilkan waktu, tempat, bentuk dan kegunaan psikologis.
Menurut Edvardsson et al [11](2005) jasa atau pelayanan juga merupakan kegiatan, proses dan interaksi serta merupakan perubahan dalam kondisi orang atau sesuatu dalam kepemilikan pelanggan.Sinambela [12](2010, hal : 3), pada dasarnya setiap manusia membutuhkan pelayanan, bahkan secara ekstrim dapat dikatakan bahwa pelayanan tidak dapat dipisahkan dengan kehidupan manusia.

B. Akademik

Akademik adalah pendidikan atau proses belajar mengajar. Akademik itu sendiri jika dilihat dari latar belakang terminologis adalah sebuah keadaan dimana orang-orang bisa menyampaikan dan menerima gagasan, pemikiran, atau ilmu pengetahuan sekaligus melakukan pengujian terhadapnya secara jujur, terbuka, dan leluasa. Febry Imam Munandar [13](2008 : 30).

\section{ANALISIS DAN PERANCANGAN SISTEM}

Sistem yang akan dirancang kali ini adalah sistem yang berfungsi untuk melakukan pengolahan data yang didapatkan dari pengisian form kuesioner yang sudah disediakan di dalam sistem. Dalam hal ini, peneliti akan meminta responden untuk mengisi form Tanya jawab yang ada di sistem dan kemudian akan diolah otomatis dengan sistem yang sudah dirancang. Sedangkan pada penelitian sebelumnya, peneliti masih harus menyebarkan kuesioner manual dan kemudian input data kesistem yang akan menghasilkan sebuah kesimpulan apakah puas atau tidak puas terhadap palayanan website. Sedangkan pada sistem yang akan dirancang oleh peneliti yang sekarang lebih mempermudah dan lebih efektif karena langsung mengisi 
form kuesioner yang ada di sistem dan diolah dengan otomatis oleh sistem. Berikut adalah alur sistem untuk proses isi.

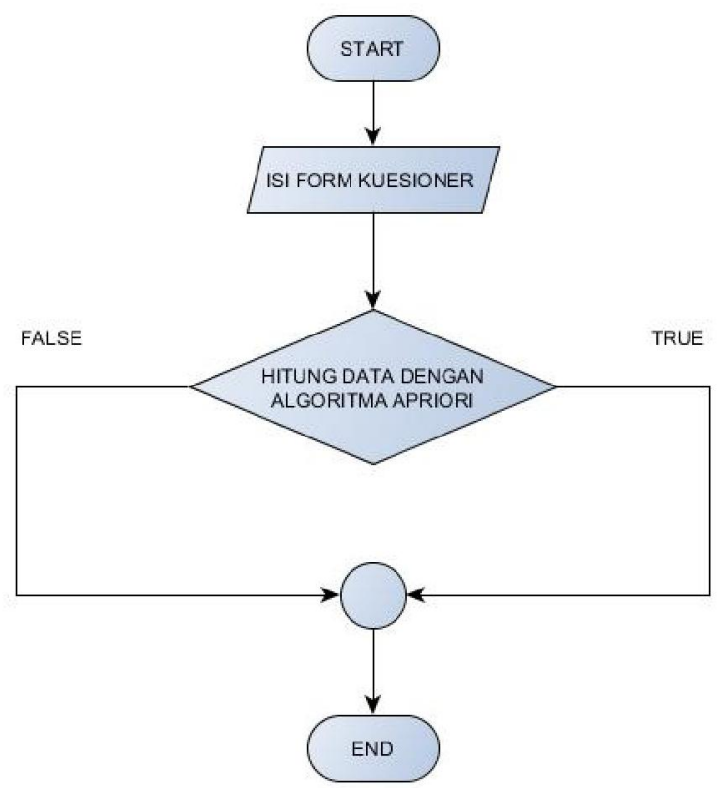

Gbr 1. Flowchart Alur Kerja Sistem

\section{A. Analisis Kebutuhan Fungsional}

Tabel 1. Kebutuhan Fungsional

\begin{tabular}{|c|c|l|}
\hline NO & AKTIFITAS & \multicolumn{1}{|c|}{ KETERANGAN } \\
\hline 1 & Admin & $\begin{array}{l}\text { Admin pada sistem ini akan } \\
\text { diberikan ruang yang } \\
\text { bertugas untuk melakukan } \\
\text { kontrol di dalam sistem } \\
\text { agar sistem selalu dapat } \\
\text { digunakan untuk } \\
\text { menginputkan data } \\
\text { mahasiswa. }\end{array}$ \\
\hline 2 & $\begin{array}{l}\text { Yang dapat melakukan } \\
\text { login kedalam sistem yaitu } \\
\text { admin dengan cara } \\
\text { memasukkan user name dan } \\
\text { password yang telah } \\
\text { dimiliki. Tujuan diberikan } \\
\text { login pada sistem agar tidak } \\
\text { semua orang dapat masuk } \\
\text { kedalam ruang kerja admin } \\
\text { dan merubah data yang ada } \\
\text { pada sistem yang dapat } \\
\text { mempengaruhi hasil dari } \\
\text { output system }\end{array}$ \\
\hline Pengolahan \\
Data
\end{tabular} \begin{tabular}{l}
$\begin{array}{l}\text { Pada proses pengolahan } \\
\text { data yang dapat melakukan } \\
\text { olah data yaitu admin. }\end{array}$ \\
\hline
\end{tabular}

\begin{tabular}{|l|l|l|}
\hline \multirow{3}{*}{} & $\begin{array}{l}\text { Admin dapat melakukan } \\
\text { olah data jika admin telah } \\
\text { benar dalam menginputkan } \\
\text { user name dan password ke } \\
\text { dalam sistem dan dapat } \\
\text { mengolah dengan cara } \\
\text { insert, update dan delete. }\end{array}$ \\
\hline 4 & $\begin{array}{l}\text { Pengguna yang } \\
\text { menggunakan sistem ini } \\
\text { yaitu } \\
\text { Pahasiswa mahasiswa. } \\
\text { menggunakan sistem ini } \\
\text { untuk melakukan pengisian } \\
\text { kuesioner }\end{array}$ \\
\hline
\end{tabular}

\section{B. Data Pertanyaan Kuisioner}

Tabel 2. Daftar Pertanyaan

\begin{tabular}{|c|c|c|c|c|c|}
\hline \multirow{2}{*}{ NO } & \multirow{2}{*}{ PERTANYAAN } & \multicolumn{4}{|c|}{ PILIHAN } \\
\hline & & SS & $\mathrm{S}$ & CS & TS \\
\hline 1 & $\begin{array}{l}\text { Sejauh mana sistem ini } \\
\text { membantu mahasiswa } \\
\text { dalam memberikan } \\
\text { informasi? }\end{array}$ & - & & & \\
\hline 2 & $\begin{array}{l}\text { Apakah sistem ini cukup } \\
\text { mudah untuk digunakan? }\end{array}$ & & - & & \\
\hline 3 & $\begin{array}{l}\text { Apakah sistem ini layak } \\
\text { digunakan? }\end{array}$ & - & & & \\
\hline 4 & $\begin{array}{l}\text { Apakah hasil yang } \\
\text { ditampilkan sistem sesuai } \\
\text { dengan kebutuhan / } \\
\text { keinqinan Anda? }\end{array}$ & & & - & \\
\hline 5 & $\begin{array}{l}\text { Apakah sistem ini } \\
\text { membosankan? }\end{array}$ & & & - & \\
\hline 6 & $\begin{array}{l}\text { Apakah sistem ini } \\
\text { memudahkan mahasiswa } \\
\text { untuk menyusun KRS? }\end{array}$ & & - & & \\
\hline 7 & $\begin{array}{l}\text { Apakah sistem ini } \\
\text { berpengaruh pada prestasi } \\
\text { mahasiswa? }\end{array}$ & - & & & \\
\hline 8 & $\begin{array}{l}\text { Bagaimana pendapat } \\
\text { Anda mengenai tampilan } \\
\text { desain dan warna pada } \\
\text { sistem ini? }\end{array}$ & & & - & \\
\hline 9 & $\begin{array}{l}\text { Sejauh mana Anda } \\
\text { memahami urutan sistem } \\
\text { ini? }\end{array}$ & & & & - \\
\hline 10 & $\begin{array}{l}\text { Bagaimana pendapat } \\
\text { Anda tentang keseluruhan } \\
\text { sistem ini? }\end{array}$ & - & & & \\
\hline
\end{tabular}

\section{Tahapan Perhitungan Algoritma Apriori}

Tahapan pertama dalam perhitungan Algoritma Apriori untuk menemukan association rules yaitu menuliskan data kuesioner yang terjadi dalam periode tertentu.Data kuesioner yang dimisalkan yaitu seperti dalam table berikut. 
Tabel 3. Perhitungan ALgoritma Apriori

untuk menemukan Association Rule

\begin{tabular}{|c|c|l|}
\hline NO & KODE & \multicolumn{1}{|c|}{ PERTANYAAN } \\
\hline 1 & P001 & $\begin{array}{l}\text { Sejauh mana sistem ini membantu } \\
\text { mahasiswa dalam memberikan } \\
\text { informasi? }\end{array}$ \\
\hline 2 & P002 & $\begin{array}{l}\text { Apakah sistem ini cukup mudah } \\
\text { untuk digunakan? }\end{array}$ \\
\hline 3 & P003 & $\begin{array}{l}\text { Apakah sistem ini layak } \\
\text { digunakan? }\end{array}$ \\
\hline 4 & P004 & $\begin{array}{l}\text { Apakah hasil yang ditampilkan } \\
\text { sistem sesuai dengan kebutuhan / } \\
\text { keinginan Anda? }\end{array}$ \\
\hline 5 & P005 & Apakah sistem ini membosankan? \\
\hline 6 & P006 & $\begin{array}{l}\text { Apakah sistem ini memudahkan } \\
\text { mahasiswa untuk menyusun KRS? }\end{array}$ \\
\hline 7 & P007 & $\begin{array}{l}\text { Apakah sistem ini berpengaruh } \\
\text { pada prestasi mahasiswa? }\end{array}$ \\
\hline 8 & P008 & $\begin{array}{l}\text { Bagaimana pendapat Anda } \\
\text { mengenai tampilan desain dan } \\
\text { warna pada sistem ini? }\end{array}$ \\
\hline 9 & P009 & $\begin{array}{l}\text { Sejauh mana Anda memahami } \\
\text { urutan sistem ini? }\end{array}$ \\
\hline 10 & P0010 & $\begin{array}{l}\text { Bagaimana pendapat Anda } \\
\text { tentang keseluruhan sistem ini? }\end{array}$ \\
\hline
\end{tabular}

Tahapan berikutnya adalah membuat tabel tabular untuk melakukan perhitungan tingkat responden kepuasan mahasiswa. Tabular ini dapat dilihat pada Tabel 4.

Tabel 4. Perhitungan Tingkat Responden

\begin{tabular}{|c|l|c|c|c|c|}
\hline \multirow{2}{*}{ NO } & \multicolumn{1}{|c|}{ PERTANYAAN } & \multicolumn{4}{|c|}{ PILIHAN } \\
\cline { 3 - 6 } 1 & $\begin{array}{l}\text { Sejauh mana sistem } \\
\text { ini membantu } \\
\text { mahasiswa dalam } \\
\text { memberikan } \\
\text { informasi? }\end{array}$ & 1 & 0 & 0 & 0 \\
\hline 2 & $\begin{array}{l}\text { Apakah sistem ini } \\
\text { cukup mudah untuk } \\
\text { digunakan? }\end{array}$ & 0 & 1 & 0 & 0 \\
\hline 3 & $\begin{array}{l}\text { Apakah sistem ini } \\
\text { layak digunakan? }\end{array}$ & 1 & 0 & 0 & 0 \\
\hline 4 & $\begin{array}{l}\text { Apakah hasil yang } \\
\text { ditampilkan sistem } \\
\text { sesuai dengan } \\
\text { kebutuhan / } \\
\text { keinginan Anda? }\end{array}$ & 0 & 0 & 1 & 0 \\
\hline 5 & $\begin{array}{l}\text { Apakah sistem ini } \\
\text { membosankan? }\end{array}$ & 0 & 0 & 1 & 0 \\
\hline 6 & $\begin{array}{l}\text { Apakah sistem ini } \\
\text { memudahkan } \\
\text { mahasiswa untuk } \\
\text { menyusun KRS? }\end{array}$ & 0 & 1 & 0 & 0 \\
\hline 7 & $\begin{array}{l}\text { Apakah sistem ini } \\
\text { berpengaruh pada } \\
\text { prestasi mahasiswa? }\end{array}$ & 1 & 0 & 0 & 0 \\
\hline 8 & $\begin{array}{l}\text { Bagaimana } \\
\text { pendapat Anda } \\
\text { mengenai tampilan } \\
\text { desain dan warna } \\
\text { pada sistem ini? }\end{array}$ & 0 & 0 & 1 & 0 \\
\hline & $\begin{array}{l}\text { Sejauh mana Anda } \\
\text { memahami urutan } \\
\text { sistem ini? }\end{array}$ & 0 & 0 & 0 & 1 \\
\hline
\end{tabular}

\begin{tabular}{|c|l|l|l|l|l|}
\hline 10 & $\begin{array}{l}\text { Bagaimana } \\
\text { pendapat Anda } \\
\text { tentang keseluruhan } \\
\text { sistem ini? }\end{array}$ & 1 & 0 & 0 & 0 \\
\hline
\end{tabular}

D. Perhitungan Algoritma Apriori

Universitas Wydiagama mempunyai sejumlah mahasiswa seperti dalam table di bawah ini. Langkah pertama buatlah association rule dari data tersebut dengan cara menghitung support dan confidence.

Dimana nilai minimum support $=0.3$ dan confidence $=0.8$ dari data di bawah ini.

Tabel 5. Perhitungan Algoritma Apriori

\begin{tabular}{|l|l|l|}
\hline No & \multicolumn{1}{|c|}{ Nama } & \multicolumn{1}{|c|}{ Tingkat Kepuasan SIM } \\
\hline 1 & Ibnu Mubarok & $\begin{array}{l}\text { \{SangatPuas=3,Memuaskan=3 } \\
\text {,CukupPuas=2,TidakPuas=2 }\end{array}$ \\
\hline 2 & $\begin{array}{l}\text { A.Sofalul } \\
\text { Khazari }\end{array}$ & $\begin{array}{l}\text { \{SangatPuas=1,Memuaskan=4 } \\
\text {,CukupPuas=1,TidakPuas=4\} }\end{array}$ \\
\hline 3 & Eva Selviana & $\begin{array}{l}\text { \{SangatPuas=4,Memuaskan=3 } \\
\text {,CukupPuas=2,TidakPuas=1\} }\end{array}$ \\
\hline 4 & $\begin{array}{l}\text { Rizky Ratna } \\
\text { Pangali }\end{array}$ & $\begin{array}{l}\text { \{SangatPuas=2,Memuaskan=3 } \\
\text {,CukupPuas=3,TidakPuas=2 }\end{array}$ \\
\hline 5 & Charisma & $\begin{array}{l}\text { \{SangatPuas=2,Memuaskan=4 } \\
\text {,CukupPuas=2,TidakPuas=2 }\end{array}$ \\
\hline 6 & $\begin{array}{l}\text { Rachmat } \\
\text { Nurseto }\end{array}$ & $\begin{array}{l}\text { \{SangatPuas=1,Memuaskan=1 } \\
\text {,CukupPuas=4,TidakPuas=4 }\end{array}$ \\
\hline 7 & $\begin{array}{l}\text { Syarif } \\
\text { Hidyatulloh }\end{array}$ & $\begin{array}{l}\text { \{SangatPuas=3,Memuaskan=3 } \\
\text {,CukupPuas=2,TidakPuas=2 }\end{array}$ \\
\hline 8 & llyas & $\begin{array}{l}\text { \{SangatPuas=4,Memuaskan=3 } \\
\text {,CukupPuas=2,TidakPuas=1 }\end{array}$ \\
\hline
\end{tabular}

Tabel 6. Hasil Perhitungan

\begin{tabular}{|l|l|l|}
\hline No & Nama & Tingkat Kepuasan SIM \\
\hline 1 & Sangat_Puas & $\{21 / 10=2,1\}$ \\
\hline 2 & Memuaskan & $\{24 / 10=2,4\}$ \\
\hline 3 & Cukup_Puas & $\{18 / 10=1,8\}$ \\
\hline 4 & Tidak_Puas & $\{18=10=1,8\}$ \\
\hline
\end{tabular}

E. Perancangan Sistem

Diagaram konteksini merupakan penggambaran sistem implementasi algoritma apriori untuk menentukan kepuasan mahasiswa terhadap SIM Online Universitas Widyagama Malang 


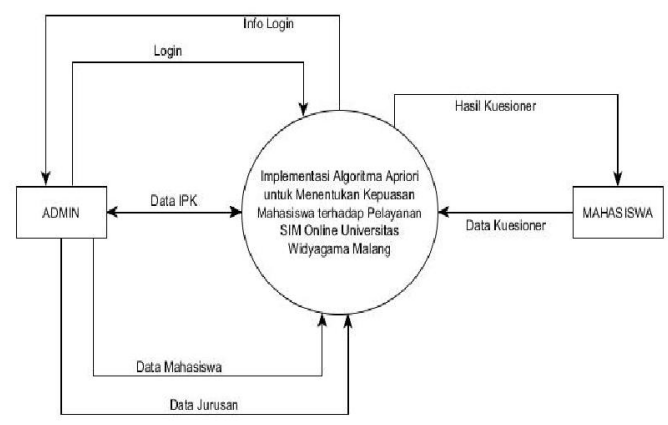

Gbr 2. Diagram Konteks

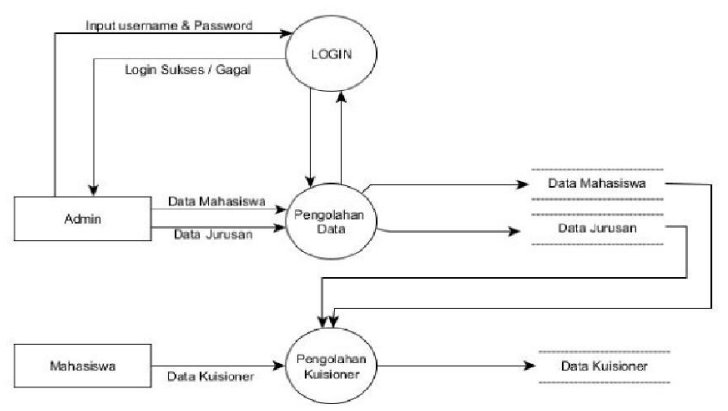

Gbr 3. DFD Level 1

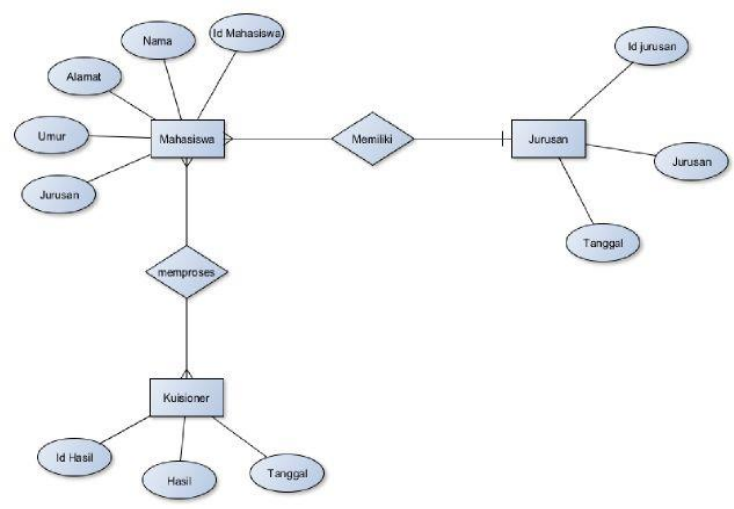

Gbr 4. ERD

\section{F. Desain User Interface}

User interface adalah cara program dan user berkomunikasi. Istilah user interface atau interface kadang-kadang digunakan sebagai penggati istilah $\mathrm{HCI}$ (Human Computer Interaction). HCI (Human Computer Interface) adalah semua aspek dari interaksi pengguna dan computer, tidak hanya hardware.

User Interface berfungsi untuk menghubungkan atau penterjemah informasi antara pengguna dengan sistem operasi, sehingga computer dapat digunakan. Dengan demikian, user interface bisa juga diartikan sebagai mekanisme inter-relasi atau integrasi total dari perangkat keras dan lunak yang membentuk pengalaman bekomputer.

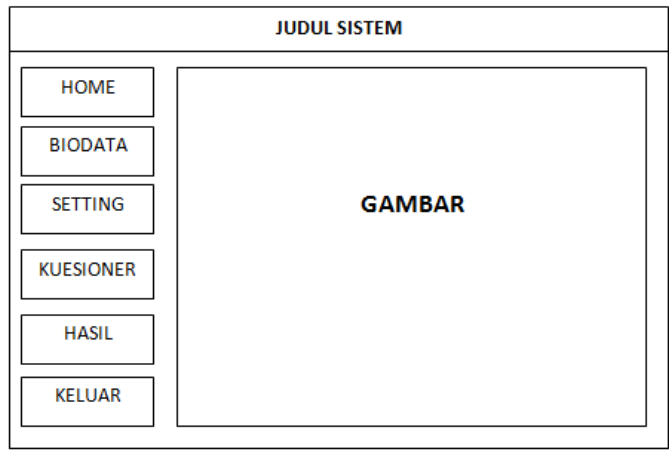

Gbr 5. Rancangan Form Halaman Pertama

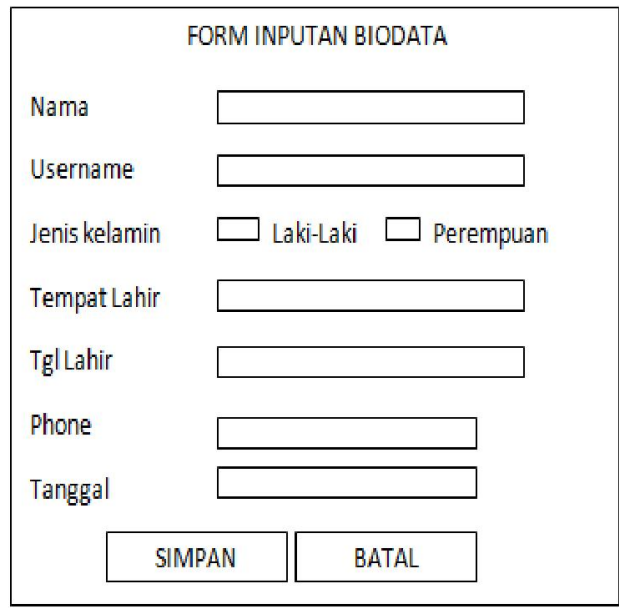

Gbr 6. Rancangan Form Input Biodata

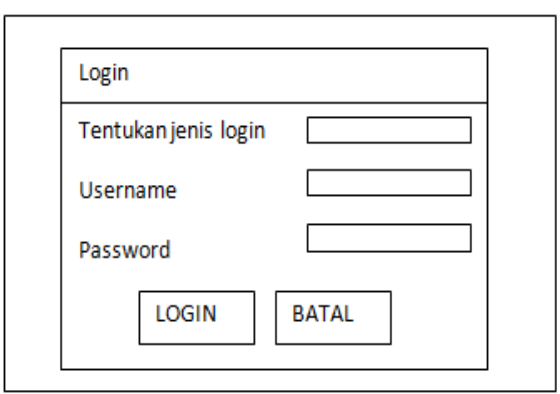

Gbr 7. Rancangan Form Setting

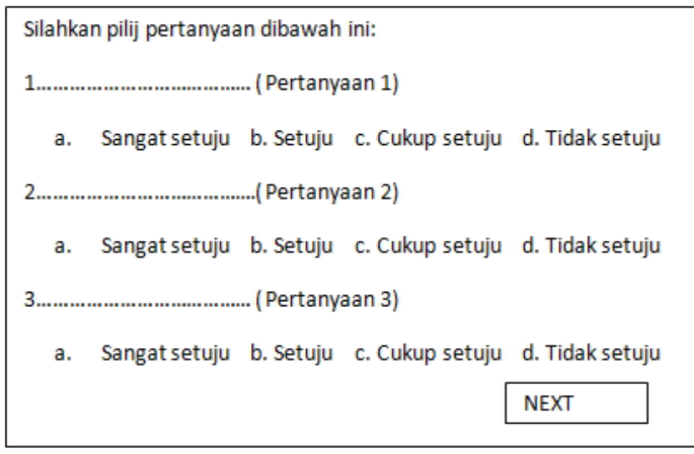


Gbr 8. Rancangan Form Kuesioner

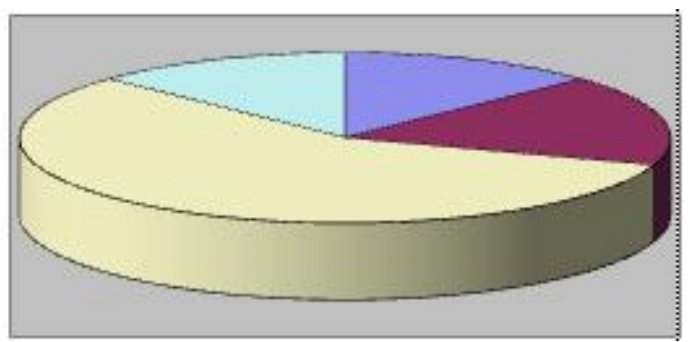

Gbr 9. Rancangan Form Hasil

\section{HASIL PENELITIAN DAN PEMBAHASAN}

Form halaman utama ini petama kali muncul saat sistem dijalankan. Form ini menampilkan menu home, biodata, setting, kuesioner, hasil dan tombol keluar. Rancangan form halaman utama dapat dilihat pada gambar di bawah ini.

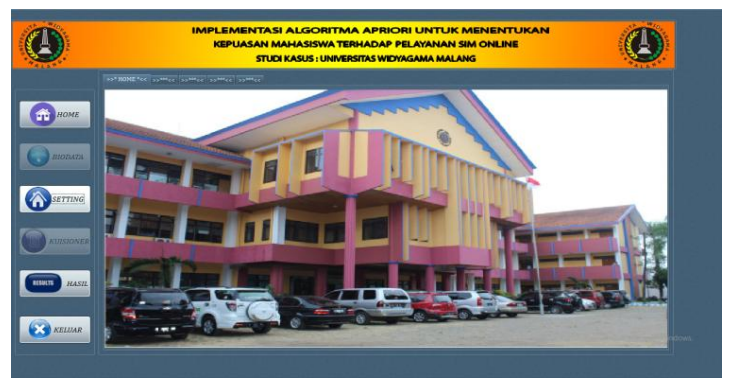

Gbr 10. Halaman Utama

Selanjutnya masuk pada menu biodata mahasiswa merupakan menu yang akan tampil saat pengguna sistem memilih menu biodata. Mahasiswa menginputkan data untuk registrasi kuesioner. Mahasiswa menginputkan nama, username, jenis kelamin, tempat lahir, tanggal lahir, phone dan tanggal. Kemudian data tersebut disimpan kedalam database mahasiswa. Tombol batal berfungsi untuk membatalkan proses simpan. Rancangan form biodata dapat dilihat pada gambar berikut.

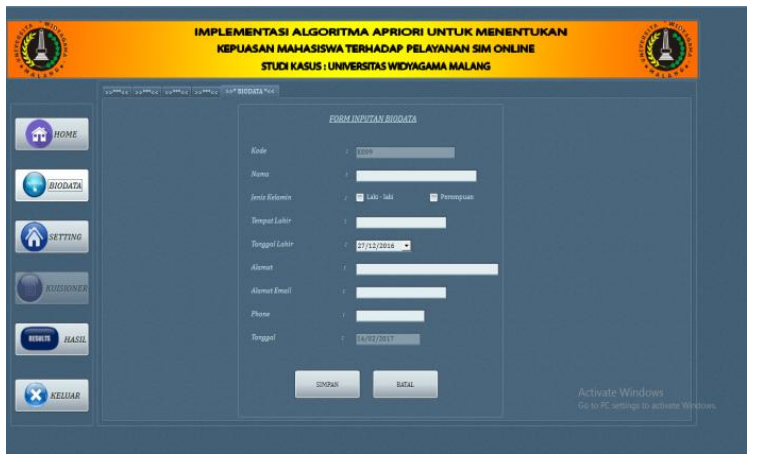

Gbr 11. Menu Biodata

Pada form setting ini admin terlebih dahulu harus login dengan menginputkan username dan password yang telah dimiliki. Form setting ini berfungsi untuk menampilkan data kuesioner yang akan dipilih mahasiswa. Rancangan form setting dapat dilihat pada gambar berikut:

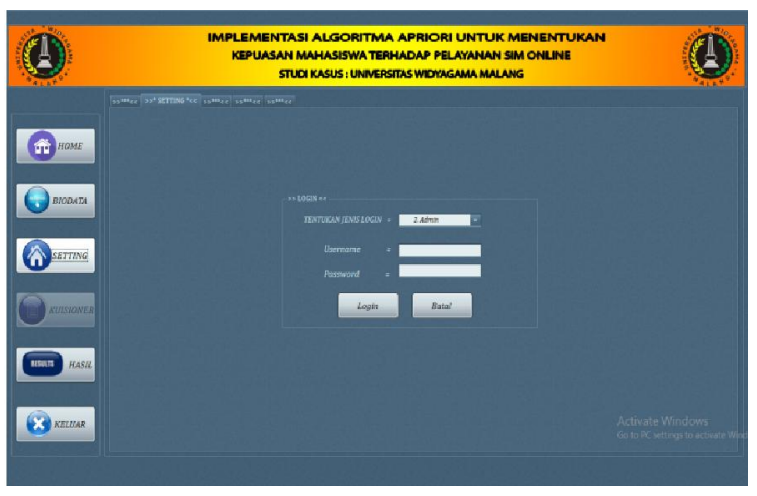

Gbr 12. Menu Setting

Form kuesioner menampilkan pertanyaan-pertanyaan mengenai tingkat kepuasan mahasiswa terhadap pelayanan SIM online di Universitas Widyagama Malang. Mahasiswa memilih setiap pertanyaan dengan pilihan sangat memuaskan, memuaskan, cukup memuaskan dan tidak memuaskan. Tombol next berfungsi untuk melihat halaman pertanyaan selanjutnya. Rancangan form kuesioner dapat dilihat pada gambar berikut: 


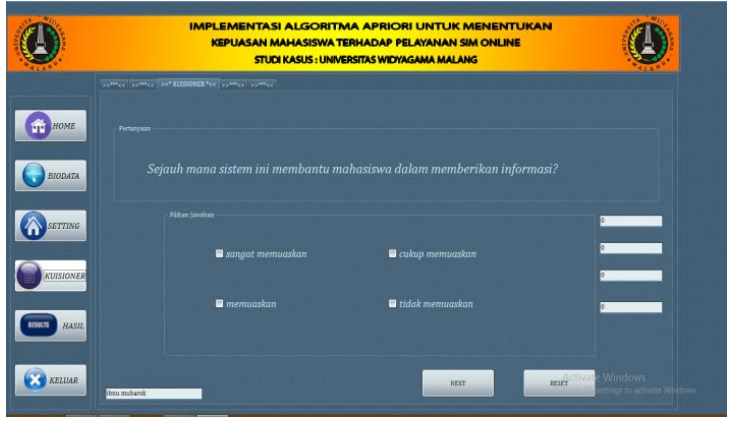

Gbr 13. Menu Kuesioner

Form hasil ini menampilkan hasil dari kuesioner yang dipilih mahasiswa berupa grafik lingkaran. Rancangan form hasil dapat dilihat pada gambar berikut ini:

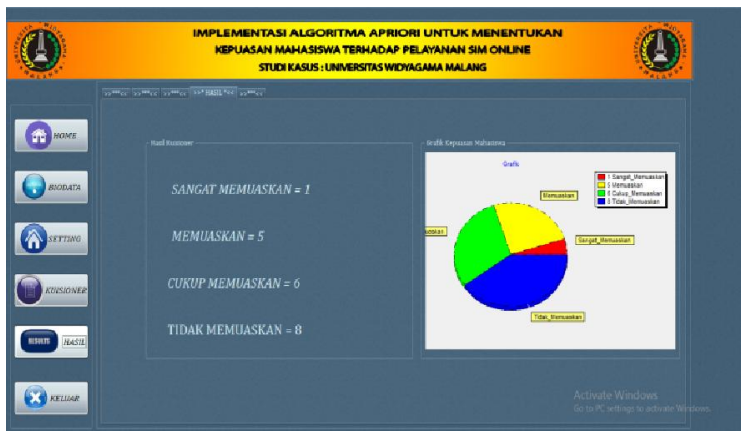

Gbr 14. Tampilan Hasil

\section{KESIMPULAN DAN SARAN}

Berdasarkan hasil implementasi dan pengujian yang telah dilakukan pada sistem "Implementasi Algoritma Apriori untuk Menentukan Kepuasan Mahasiswa Terhadap Pelayanan SIM Online Universitas Widyagama Malang" penerapan data mining dengan menggunakan metode Algoritma Apriori dan dapat diambil kesimpulan sebagai berikut :

1. Aplikasi yang dibangun menggunakan algoritma apriori dapat meminimalkan masalah yang terjadi pada algoritma apriori.

2. Aplikasi yang dibangun menggunakan algoritma apriori dapat mengoptimalikasi waktu pemrosesan dalam pencarian pola kepuasan pelayanan.

\section{REFERENSI}

Kotler, P., \& Kevin, L. K. (2012). Marketing Management. New Jersey: Prentice Hall.

Buchari, A. (2011). Manajemen Pemasaran dan Pemasaran Jasa. Bandung: Penerbit Alfabeta.

Han, J., \& Kamber, M. (2011). Data Mining: Concept and Techniques. Waltham: Elsevier Inc.

Linoff, G. S., \& Berry, M. J. (2011). Data Mining Techniques for Marketing, Sales, Customer Relationship Management. United States of America: Wiley Publishing, Inc.

Agusta, Y. (2007). K-Means-Penerapan, Permasalahan dan Metode terkait. Jurnal Sistem dan Informatika , 47-60.

Santosa, B. 2007. Data Mining:

TeknikPemanfaatan Data untukKeperluanBisnis.

Yogyakarta: Grahallmu

Sinambela, LijanPoltak. 2006. Reformasi Pelayanan Publik:Teori, Kebijakan, danImplementasi. Jakarta: PT. BumiAksara.

Lupiyoadi, Rambat. 2001. Manajemen Pemasaran Jasa. Jakarta : PT. Salemba Empat.

Parasuraman. A., Zeithaml, V.A. dan Berry, L.L (1994), "Reassessment of Expectations as a Comparison Standar in Measuring Service Quality:

Implication for Further Research, “Journal of Marketing, January (58): $111-124$.

Nurullah. 2012. Perancangan Dan Pembuatan Sistem Informasi Akuntansi Pada Stmik U'budiyah Menggunakan Vb.Net, Vol1.No.7 Hal.39-69.

Suroto. 1992. Strategi Pembangunan dan Perencanaan Kesempatan Kerja. Gadjah Mada University Press, Yogyakarta 
